\title{
White esophagus accompanying multiple circumferential duodenal erosions extending to upper jejunum
}

\author{
Akinori Kanzaki ${ }^{1}$, Tetsuo Maeda ${ }^{2}$, Akihito Otsuka ${ }^{2}$, Kikuo Ichihara ${ }^{2}$, Hidenori Koyama ${ }^{3}$, \\ Satoru Katayama ${ }^{1}$, and Tadashi Nakamura ${ }^{2}$ \\ ${ }^{1}$ Hyogo College of Medicine Sasayama Medical Center \\ ${ }^{2}$ Medical Corporation Kawasaki Hospital \\ ${ }^{3}$ Hyogo College of Medicine
}

September 21, 2020

\begin{abstract}
White esophagus is an extremely rare disease and recognized to be the result of chronic ischemic injury. We report here successful treatment of a case of white esophagus accompanying multiple areas of circumferential duodenal erosion extending to the upper jejunum in a middle-aged male.
\end{abstract}

\section{Case presentation}

A 51-year-old male complaining of heartburn from three weeks prior was admitted to our hospital. He did not use non-steroidal anti-inflammatory drug. Vital signs and laboratory analysis findings were not remarkable. Mediastinal lesion was not observed in a computed tomographic scan. An upper endoscopy examination showed diffuse sloughing and erosion reaching to the upper esophagus, as well as circumferential erosions on Kerckring folds from the second portion of the duodenum to the upper jejunum (Figure 1). Histological results indicated necrotic tissue in the esophagus, and chronic inflammation in the duodenum and jejunum (Figure 2). After seven days of fasting and transfusion therapy with a proton-pump inhibitor, second-look endoscopy findings demonstrated improvement of all lesions.

\section{Question}

What was the diagnosis?

\section{Answer}

The diagnosis was white esophagus accompanying erosions from the duodenum to upper jejunum. White esophagus is an extremely rare disease associated with chronic ischemia. ${ }^{1}$ Duodenal lesions are occasionally accompanied by black esophagus ${ }^{2}$, which has a relationship with white esophagus, though it has been hardly discussed and no pictures has been shown. This is the first report that includes images of duodenal and jejunum lesions in a patient with white esophagus. The present case increases understanding regarding the clinical significance of white esophagus. 


\section{Conflicts of interest}

\section{None to declare.}

\section{Authors' contributions}

AK contributed to writing the text. TM, AO, KI, HK, SK, and TN approved the final version of the manuscript.

\section{Consent statement}

\section{Informed consent for publication of anonymous details was obtained.}

\section{References}

1. Konstantinos Blouhos, Konstantinos A Boulas, Konstantinos Tsalis, Anestis, Hatzigeorgiadis. 2018. White oesophagus. Lancet Gastroenterol Hepatol 3: 444.

2. Augusto F, Fernandes V, Cremers MI, et al. 2004. Acute necrotizing esophagitis: A large retrospective case series. Endoscopy 36:411-415.

Figure legends

Figure 1

First-look endoscopy revealed (A) diffuse sloughing and erosion reaching to the upper esophagus, as well as (B) circumferential erosions on Kerckring folds from the second portion of the duodenum to (C) the upper jejunum.

\section{Figure 2}

Histological findings of the (A) esophagus, (B) duodenum, and (C) (D) upper jejunum showing necrotic tissue in the esophagus, chronic inflammation in the proper mucosal layer and partial goblet cell depletion in the second portion, and partial areolation disorder in the upper jejunum.
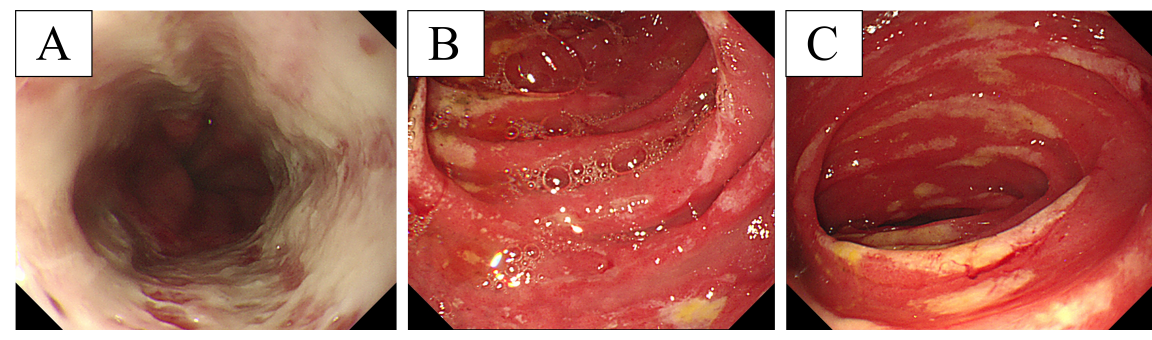

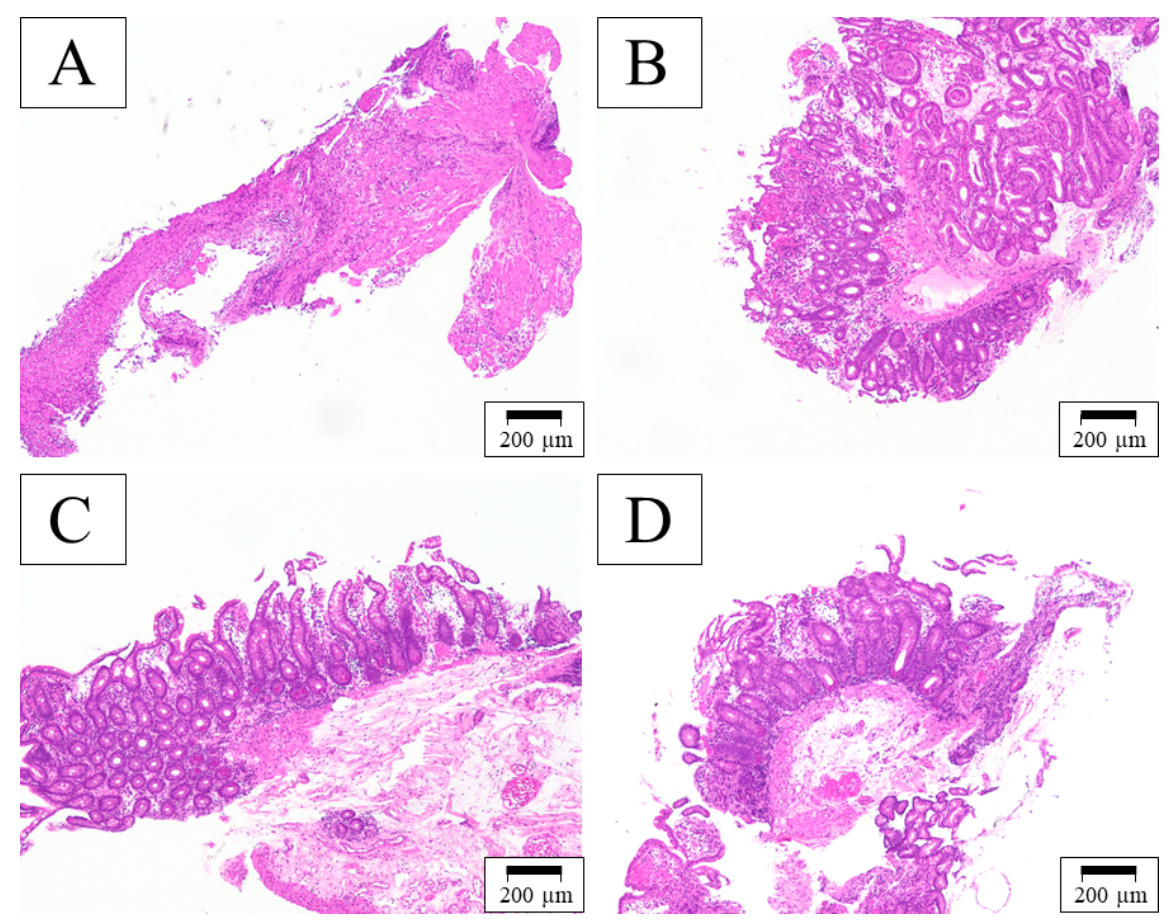